\title{
CORRECTION
}

\section{Correction to: EQRAIN: uranium and plutonium interlaboratory exercises from 1997 to 2016-comparison to ITVs-2010}

\author{
${\text { Marielle } \text { Crozet }^{1} \text { (D) Danièle Roudil }}^{1} \cdot$ Corinne Rigaux $^{1} \cdot$ Caroline Bertorello $^{1} \cdot$ Sébastien Picart $^{1} \cdot$ Christophe Maillard $^{2}$
}

Published online: 12 June 2019

○) Akadémiai Kiadó, Budapest, Hungary 2019

\section{Correction to: \\ Journal of Radioanalytical and Nuclear Chemistry (2019) 319:1013-1021 \\ https://doi.org/10.1007/s10967-018-6399-7}

In the original publication of the article, the values of $u(s), u(r)$ and $I T V$ for HKED were published incorrectly in Table 6 . The correct version of Table 6 is provided in this correction.
Publisher's Note Springer Nature remains neutral with regard to jurisdictional claims in published maps and institutional affiliations.
Table 6 Measurement method uncertainties from EQRAINs U and corresponding ITVs-2010 (\%)

\begin{tabular}{|c|c|c|c|c|c|c|c|}
\hline & \multicolumn{4}{|l|}{ EQRAIN U } & \multicolumn{3}{|c|}{ ITVs-2010 } \\
\hline & Number of $d_{i j}$ & $u_{r e l}(x)_{s}$ & $u_{r e l}(x)_{r}$ & $u_{r e l}(x)$ & $u(s)$ & $u(r)$ & ITV \\
\hline GRAV & 45 & 0.01 & 0.16 & 0.16 & 0.05 & 0.05 & 0.07 \\
\hline TITRI (MALL) & 33 & 0.05 & 0.06 & 0.08 & 0.1 & 0.1 & 0.14 \\
\hline TITRI (D\&G) & 119 & 0.04 & 0.11 & 0.12 & 0.1 & 0.1 & 0.14 \\
\hline IDMS & 74 & 0.03 & 0.12 & 0.13 & 0.1 & 0.15 & 0.18 \\
\hline $\mathrm{XRF} *$ & 42 & 0.11 & 0.27 & 0.29 & 2 & 2 & 2.8 \\
\hline HKED** & 40 & 0.05 & 0.19 & 0.20 & 0.2 & 0.2 & 0.28 \\
\hline
\end{tabular}

*ITVs-2010: 1 to $50 \mathrm{~g} / \mathrm{L} \mathrm{U}$

**ITVs-2010: typically 150 to $250 \mathrm{~g} / \mathrm{L} \mathrm{U}$ with a $\mathrm{U} / \mathrm{Pu}$ ratio of 80 to 150 and measurement time of $3 \times 1000 \mathrm{~s}$

The original article can be found online at https://doi.org/10.1007/ s10967-018-6399-7.

\section{Marielle Crozet}

marielle.crozet@cea.fr

1 CEA Nuclear Energy Division, Research Department of Mining and Fuel Recycling, Analysis Method Establishment Commission (CETAMA), 30 207, Bagnols-Sur-Cèze, France

2 CEA Nuclear Energy Division, Research Department of Mining and Fuel Recycling, Atalante Analysis Laboratory (L2AT), 30 207, Bagnols-Sur-Cèze, France 